\title{
Early structural valve deterioration of 18-mm Sorin Soprano aortic pericardial bioprosthesis
}

\author{
Luis Fernando López Almodóvar, MD, Pedro Lima, MD, Alfonso Cañas, MD, José Buendía, MD, and \\ Emilio Monguió, MD, Toledo, Spain
}

Structural valve deterioration has been defined as any changes intrinsic to the prosthetic valve leading to either stenosis or regurgitation. Factors associated with structural valve dysfunction include wear, calcification, leaflet tear, and stent creep. We present the case of a patient with 18$\mathrm{mm}$ Sorin Soprano aortic pericardial bioprosthesis (Sorin Biomedica Cardio SpA, Saluggia, Italy) with significant aortic valve stenosis and regurgitation necessitating explantation 2 years after the initial procedure. Cases of immediate structural dysfunction with this prosthesis have not yet been reported.

\section{CLINICAL SUMMARY}

A 72-year-old man was admitted to our institution with severe aortic valve stenosis. He had a severely calcified trileaflet aortic valve. An aortic valve replacement with an 18-mm Sorin Soprano pericardial valve was performed with 2-0 pledgeted mattress sutures. Routine transthoracic echocardiography performed on postoperative day 5 showed an elevated peak transvalvular gradient $(57 \mathrm{~mm} \mathrm{Hg})$, but the patient had no symptoms and was discharged home. The patient did well for 2 years, at which time symptomatic deterioration with dyspnea was seen. Transthoracic echocardiography revealed aortic prosthesis dysfunction with severe stenosis and moderate regurgitation.

A reoperation was performed, and examination of the prosthesis before explantation showed the valve to be well seated in the supra-annular position. The prosthesis was stenotic because of intrinsic and vegetating calcifications in all leaflets, and a calcified tear in the noncoronary leaflet resulted in a lack of leaflet coaptation, causing aortic regurgitation (Figure 1). The valve was replaced with a $19-\mathrm{mm}$ mechanical valve. The patient recovered completely and was discharged uneventfully.

From the Cardiac Surgery Department, Virgen de la Salud Hospital, Toledo, Spain. Disclosures: None.

Sorin Soprano is manufactured by Sorin Biomedica Cardio SpA, Saluggia, Italy.

Received for publication Dec 2, 2008; accepted for publication Dec 24, 2008; available ahead of print Feb 23, 2009.

Address for reprints: Luis Fernando López Almodóvar, MD, Cardiac Surgery Departament, Virgen de la Salud Hospital, Toledo 45004, Spain (E-mail: lopezalmodovar@ yahoo.es).

J Thorac Cardiovasc Surg 2010;139:e66-7

$0022-5223 / \$ 36.00$

Copyright (c) 2010 by The American Association for Thoracic Surgery doi:10.1016/j.jtcvs.2008.12.022

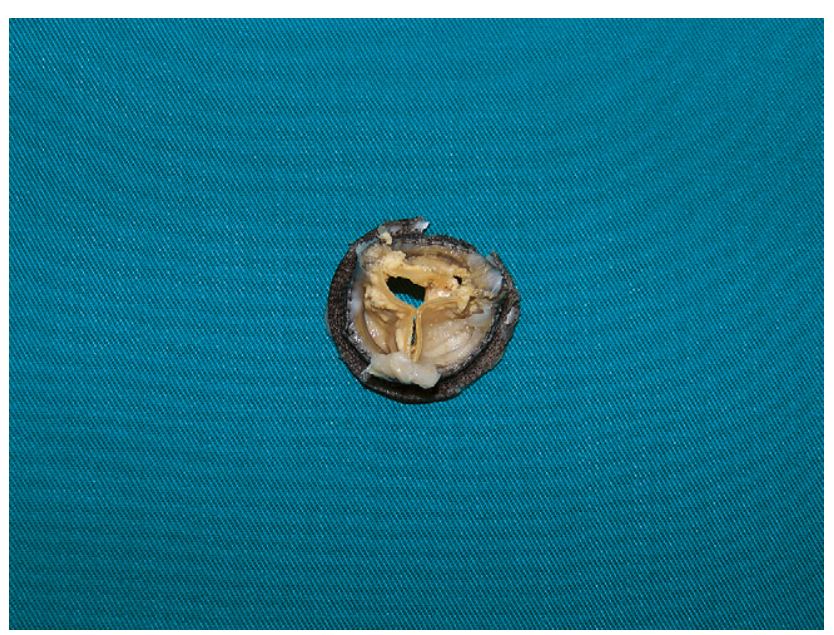

FIGURE 1. Explanted prosthesis shows intrinsic and vegetating calcifications in all leaflets with calcified tear in noncoronary leaflet.

\section{DISCUSSION}

Pericardial valve prosthesis has been associated with excellent long-term clinical results, and immediate structural valve deterioration is rare. ${ }^{1}$ Structural valve deterioration includes changes intrinsic to the valve, including wear, calcification, leaflet tear, and stent creep, but excludes infection or thrombosis, as determined at explantation. ${ }^{2}$ In most patients, calcification is the cause of structural valve dysfunction requiring explantation.

The Sorin Soprano valve, a pericardial tissue valve designed for a totally supra-annular seating, is in widespread use in Europe. ${ }^{3}$ It has been marketed since May 2003. Valve leaflets are manufactured in a unique two-sheet design with glutaraldehyde-stabilized bovine pericardium posttreated with a detoxification process. The exclusive detoxification treatment with homocysteic acid neutralizes residues of unbound aldehyde groups after the fixation process. The product thus does not contain glutaraldehyde residues and is therefore ready to implant without rinsing.

Sorin Biomedica Cardio was contacted, and the prosthesis was sent to the manufacturer for analysis. Sorin has confirmed that the cause of this valve structural deterioration was related to large intrinsic and vegetating calcifications affecting all the leaflets and causing stenosis (mean calcification score 3.33 out of 4). This prosthesis was initially stenotic because of intrinsic and vegetating calcifications in all leaflets and subsequently became insufficient because of tears. In this case, 
a calcified tear in the noncoronary leaflet with perforation was observed. It is difficult to determine whether the tear was primary or calcium related. ${ }^{4}$ Probably, the presence of these calcium depositions encouraged tearing. We speculate that the postoperative finding of elevated peak transvalvular gradient was associated with a dynamic obstruction in the left ventricular outlet, and this situation led to mechanical stress during the systolic phase. The right coronary leaflet had intrinsic and vegetating calcifications with stiffness but without tearing. In addition, the commissural areas were severely calcified. These areas are designed to absorb and distribute the mechanical stress during the cardiac cycle. Thus when the leaflets are opened, they are completely free of stresses. Although a stent distortion is extremely rare and unusual, we can not reject this possibility completely.
The Sorin Biomedica Cardio technical report concludes that in presence of severe aortic stenosis and massive calcification before the implant, calcifications may have been triggered by the presence of such risk factors as hyperlipidemia and hypercholesterolemia.

\section{References}

1. Fleisher AG, Lafaro RJ, Moggio RA. Immediate structural valve deterioration of 27-mm Carpentier-Edwards aortic pericardial bioprosthesis. Ann Thorac Surg. 2004;77:1443-1445

2. Akins CW, Miller DC, Turina MI, Kouchoukos NT, Blackstone EH, Grunkemeier GL, et al. Guidelines for reporting mortality and morbidity after cardiac valve interventions. J Thorac Cardiovasc Surg. 2008;135:732-738.

3. Pavoni D, Badano LP, Musumeci SF, Frassani R, Gianfagna P, Mazzaro E, et al Results of aortic valve replacement with a new supra-annular pericardial stented bioprosthesis. Ann Thorac Surg. 2006;82:2133-2138.

4. Thiene G. Durability of valve bioprosthesis and the need of careful examination of explants. Ann Thorac Surg. 2006;82:2337-2342.

\title{
Complete destruction of a tissue-engineered porcine xenograft in pulmonary valve position after the Ross procedure
}

\author{
Nicola E. Hiemann, MD, ${ }^{\mathrm{a}}$ Marjam Mani, MD, ${ }^{\mathrm{b}}$ Michael Huebler, MD, ${ }^{\mathrm{a}}$ Rudolf Meyer, MD, PhD, \\ Roland Hetzer, MD, PhD, ${ }^{a}$ Roland Thieme, MD, ${ }^{\mathrm{b}}$ and Christian Bethge, MD, PhD, ${ }^{\mathrm{b}}$ Berlin, Germany
}

The Ross procedure is an attractive technique for aortic valve replacement using a viable pulmonary autograft. Current data from the German Ross Registry show favorable clinical and hemodynamic results. ${ }^{1}$ Pilot work on the use of a tissue-engineered decellularized porcine xenograft for right ventricular outflow tract reconstruction has reported excellent early and midterm results. ${ }^{2,3}$ We report a case of recurrent right-sided heart failure after the Ross procedure caused by complete destruction of the pulmonary xenograft.

\section{CLINICAL SUMMARY}

A 61-year-old male patient underwent the Ross procedure for calcified aortic valve stenosis and received a tissue-engi-

\footnotetext{
From the Deutsches Herzzentrum Berlin, Department of Cardiothoracic and Vascular Surgery, ${ }^{\text {a } B e r l i n, ~ G e r m a n y ; ~ a n d ~ J u ̈ d i s c h e s ~ K r a n k e n h a u s ~ B e r l i n, ~ D e p a r t m e n t ~ o f ~}$ Internal Medicine and Cardiology, ${ }^{\mathrm{b}}$ Berlin, Germany.

Disclosures: None.

Received for publication Oct 9, 2008; accepted for publication Dec 30, 2008; available ahead of print Feb 23, 2009.

Address for reprints: Christian Bethge, MD, PhD, Jüdisches Krankenhaus Berlin, Department of Internal Medicine and Cardiology, Heinz-Galinski-Strasse 1, 13347 Berlin, Germany (E-mail: christian.bethge@jkb-online.de)

J Thorac Cardiovasc Surg 2010;139:e67-8

0022-5223/\$36.00

Copyright (c) 2010 by The American Association for Thoracic Surgery

doi:10.1016/j.jtcvs.2008.12.033
}

neered porcine xenograft (Matrix P, diameter $28 \mathrm{~mm}$; AutoTissue GmbH, Berlin, Germany) for reconstruction of the right ventricular outflow tract. Four weeks after surgery, severe dyspnea developed in the patient, and the chest $\mathrm{x}$-ray indicated abundant right-sided pleural effusion without evidence of pulmonary infection in computed tomography, bronchoscopy, or serology. Because of refractory pleural transudation, the patient underwent right-sided partial pleurectomy. Ten months later, he presented with severe dyspnea and progressive weight loss ( $35 \mathrm{~kg}$ since Ross operation). Outpatient echocardiography showed a pulmonary peak velocity of $1.5 \mathrm{~m} / \mathrm{s}$ without any signs of regurgitation, preserved left ventricular ejection fraction, and minimal aortic autograft regurgitation. Because objective physical fitness was good (100W in ergometry), the patient was scheduled for ambulatory follow-up 2 weeks later. Echocardiography revealed enlargement of the right ventricle and moderate hypertrophy. Morphologic evaluation of the pulmonary xenograft was scarcely feasible. Mean and peak pulmonary pressure gradients were 10 and $22 \mathrm{~mm} \mathrm{Hg}$, respectively; peak velocity was $1.9 \mathrm{~m} / \mathrm{s}$, and there was mild early diastolic regurgitation. Systolic pulmonary pressure was estimated at $55 \mathrm{~mm} \mathrm{Hg}$, indicating moderate to severe pulmonary hypertension. Two weeks later the patient was hospitalized again for severe dyspnea and newly developed left-sided pleural effusion. Transthoracic echocardiography demonstrated progressive 